\title{
The reaction of a bis(spirodienone) calix[4]arene derivative with hydrazine
}

\author{
Flavio Grynszpan and Silvio E. Biali \\ Department of Organic Chemistry, The Hebrew University of Jerusalem, \\ Jerusalem 91904, Israel \\ E-mail:silvio@vms.huji.ac.il
}

Dedicated to Professor Zhi-Tang Huang

(received 28 Oct 02; accepted 04 Dec 02; published on the web 20 Dec 02)

\begin{abstract}
Reaction of the bis(spirodienone) calixarene derivative 2a with hydrazine afforded a reduction product (the monospiro allyl alcohol derivative 4) that was characterized by NMR spectroscopy and X-ray crystallography.
\end{abstract}

Keywords: Calixarenes, spirodienone, synthesis

\section{Introduction}

The calixarenes are synthetic macrocycles that are presently extensively studied as building blocks for the construction of molecular hosts. ${ }^{1}$ Oxidation of the parent $p$-tert-butylcalixarene $\mathbf{1}$ with a tetraalkylammonium tribromide salt in a basic media affords a mixture of three isomeric bis(spirodienone) calixarene derivatives $(\mathbf{2 a - 2 c}){ }^{2-5}$ These compounds can be separated by chromatography but upon heating they mutually isomerize. In 1998 Huang and coworkers described a useful modification of the oxidation reagent which enables isolating the major bis(spirodienone) product (2a) without resorting to chromatography. ${ }^{6}$

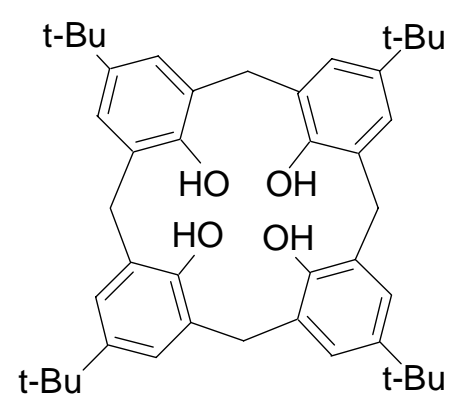

1

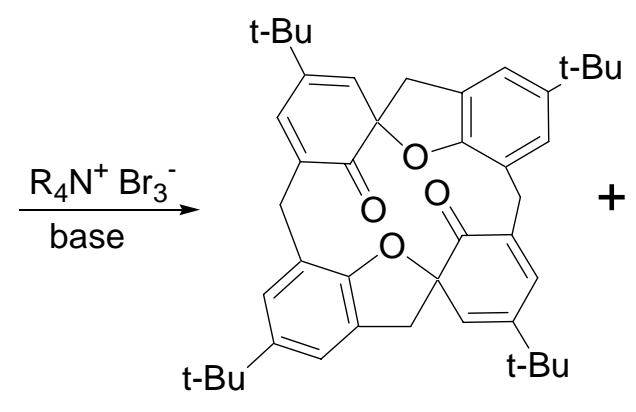

$2 \mathbf{a}(R S)$

$\mathbf{2 b}(R R / S S)$

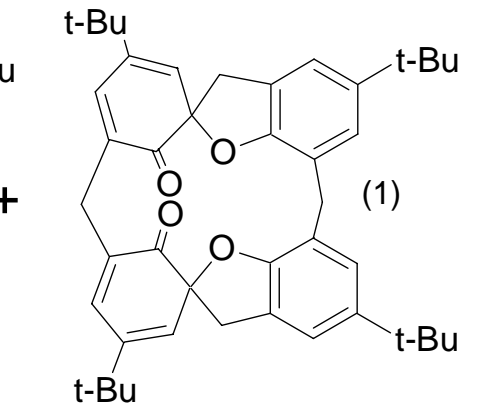

2c (RS) 
The spirodienone calixarene derivatives are useful synthetic intermediates which have been utilized inter alia for the synthesis of calixarene derivatives where two $\mathrm{OH}$ groups have been replaced by methyls, ${ }^{7 a}$ for achieving selective extraannular modifications (such as chlorode-tert-butylation reactions), ${ }^{2 b}$ for the preparation of calixarene derivatized at two proximal (i.e., vicinal) rings, ${ }^{7 b}$ for the synthesis of xanthenocalixarene derivatives ${ }^{8}$ and for the selective functionalization of two methylene groups in a trans fashion. ${ }^{9}$

The partial or total replacement of the intraannular oxygens of $\mathbf{I}$ by nitrogen atoms is of particular interest. The introduction of basic groups may dramatically modify the binding properties of the systems. We attempted in the past, ${ }^{10 a}$ the preparation of aminocalix[4]arenes by the route of Rossi and Bunnett (i.e., phosphorylation of the $\mathrm{OH}$ groups followed by treatment with $\left.\mathrm{K} / \mathrm{KNH}_{2} / \mathrm{NH}_{3}\right){ }^{11}$ This approach resulted in the formation of OH-depleted calixarenes. ${ }^{10}$ Shinkai and coworkers reported the preparation of a distal 1,3-diaminocalix[4]arene derivative in low yield, as one of the products of the reaction of a 1,3-bis(diethylphosphate) ester of la with $\mathrm{KNH}_{2} / \mathrm{NH}_{3}$ using THF/HMPA as cosolvents. ${ }^{12}$ Recently, Miyano and coworkers described the preparation of a tetraaminothiacalixarene derivative. The key step of the reaction sequence involved nucleophilic aromatic substitution at the aryl rings. This reaction is facilitated by the presence of strong electron withdrawing groups $\left(\mathrm{SO}\right.$ and $\left.\mathrm{SO}_{2}\right)$ at the bridging positions of the macrocycle. $^{13}$

In principle the reaction of the spirodienone systems with hydrazine could enable the preparation of both hydrazo and aminocalixarene derivatives. We have described in the past the reaction of mono(spirodienone) calixarene derivatives $\mathbf{3 a}$ and $\mathbf{3 b}$ with amino nucleophiles as a synthetic route for the preparation of the monoaminocalixarenes. ${ }^{8 a}, 14$ Here we describe the reaction of the bis(spirodienone) calixarene derivative 2a with hydrazine and the spectroscopic and crystal data of the product obtained.

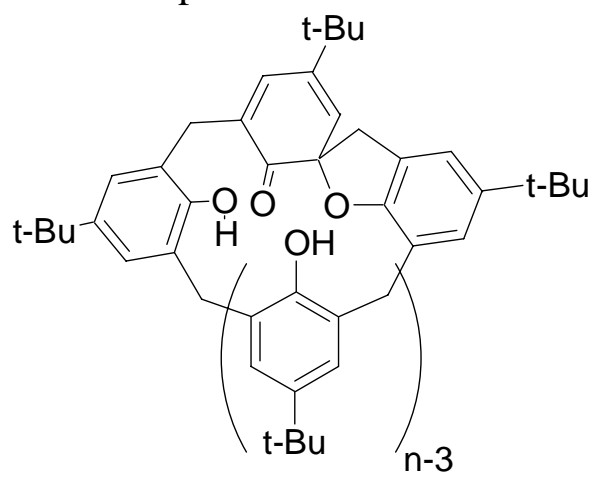

$3 a n=4$

$3 b n=5$

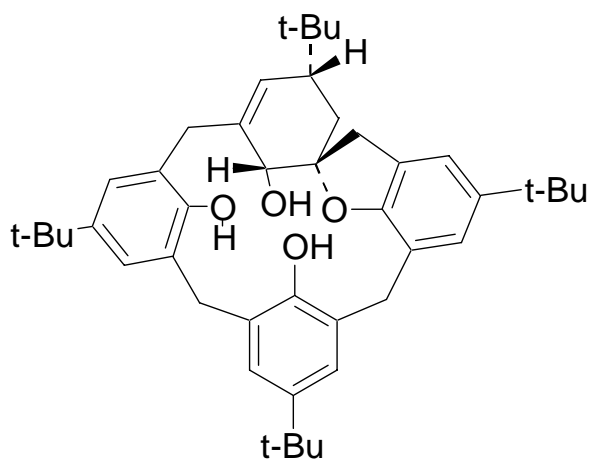

4

\section{Results and Discussion}

\section{Reaction of bis(spirodienone) calixarene 2a with hydrazine}

Reaction of 2a with hydrazine hydrate in isopropanol at $160^{\circ} \mathrm{C}$ (in a pressure reactor) did not yield the expected dihydrazo derivative. A colorless material (CI MS: m/z $649.0\left(\mathrm{MH}^{+}\right)$) was 
obtained in $17 \%$ yield from the reaction together with $\mathbf{l}$. The p-tert-butylcalix[4]arene was separated by trituration with $\mathrm{MeOH}$ and the colorless material was recrystallized from $\mathrm{CH}_{2} \mathrm{Cl}_{2}$ / MeCN. The ${ }^{1} \mathrm{H}$ NMR spectrum of the product (400 $\mathrm{MHz}, \mathrm{CDCl}_{3}$ ) displayed four tert-Bu signals, one of them upfield shifted and broader than the rest $(\delta 0.86 \mathrm{ppm})$, eight aliphatic signals integrating for twelve protons, a vinyl proton at $5.65 \mathrm{ppm}$, a broad singlet at $6.08 \mathrm{ppm}$ which disappeared when a drop of $\mathrm{D}_{2} \mathrm{O}$ was added to the sample. Five signals (integrating for six protons) in the $\delta 6.65-7.43 \mathrm{ppm}$ region were observed for the aromatic protons (Figure 1). If the reaction resulted in the replacement of one or two oxygens by a nitrogen-containing group, the product would have been expected to display basic properties. However, when $p$-toluenesulfonic acid was added to a sample of the compound in $\mathrm{CDCl}_{3}$ neither dissolution of the acid nor a change in the chemical shifts were observed.

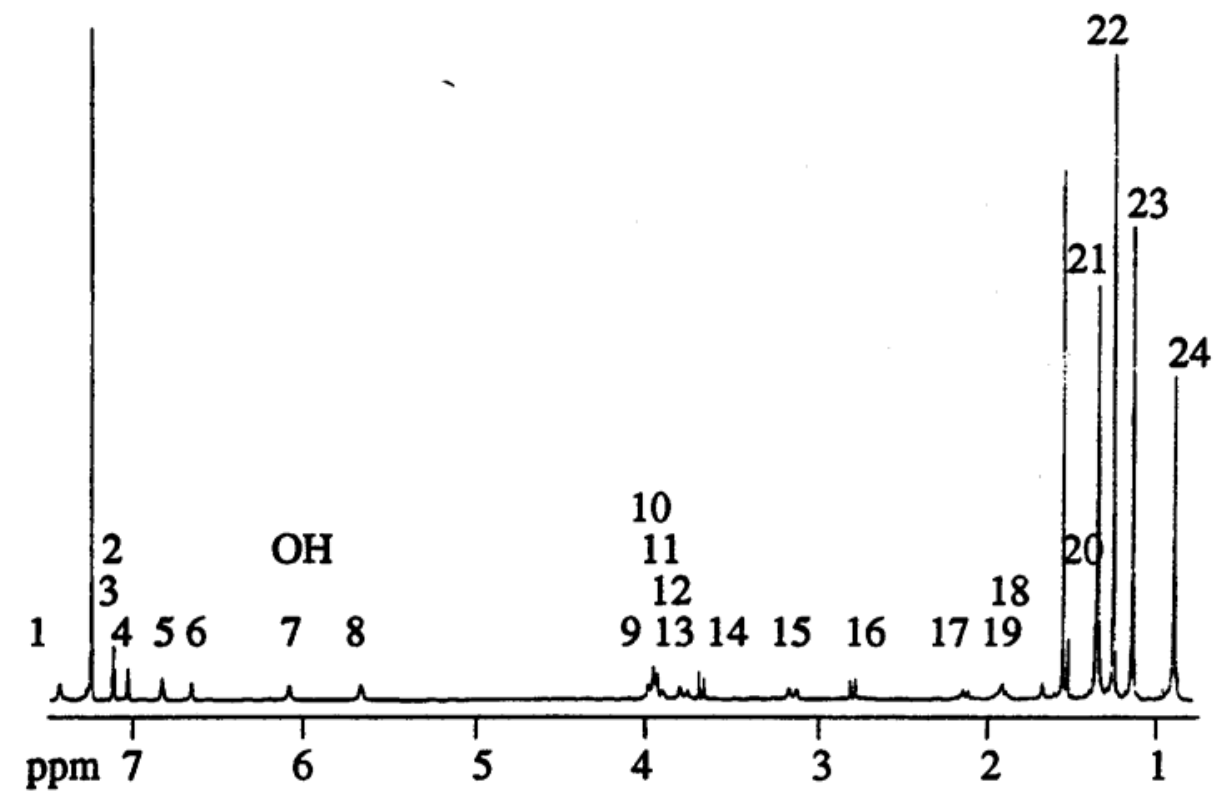

Figure 1. $400 \mathrm{MHz}{ }^{1} \mathrm{H}$ NMR spectrum of the product 4.

The ${ }^{13} \mathrm{C}$ NMR spectrum (100.62 $\mathrm{MHz}, \mathrm{CDCl}_{3}$ ) of the isolated product displayed two characteristic signals, one resonating at $\delta 66.89 \mathrm{ppm}$, in agreement with a secondary carbon of an alcohol, and another at $\delta 91.47 \mathrm{ppm}$, which could be assigned to a spiro carbon. The signal resonating at $6.08 \mathrm{ppm}$ was assigned to a proton belonging to a secondary alcohol group. In order to assign the ${ }^{1} \mathrm{H}$ NMR signals, 2D DQF-COSY and NOESY experiments were performed. 


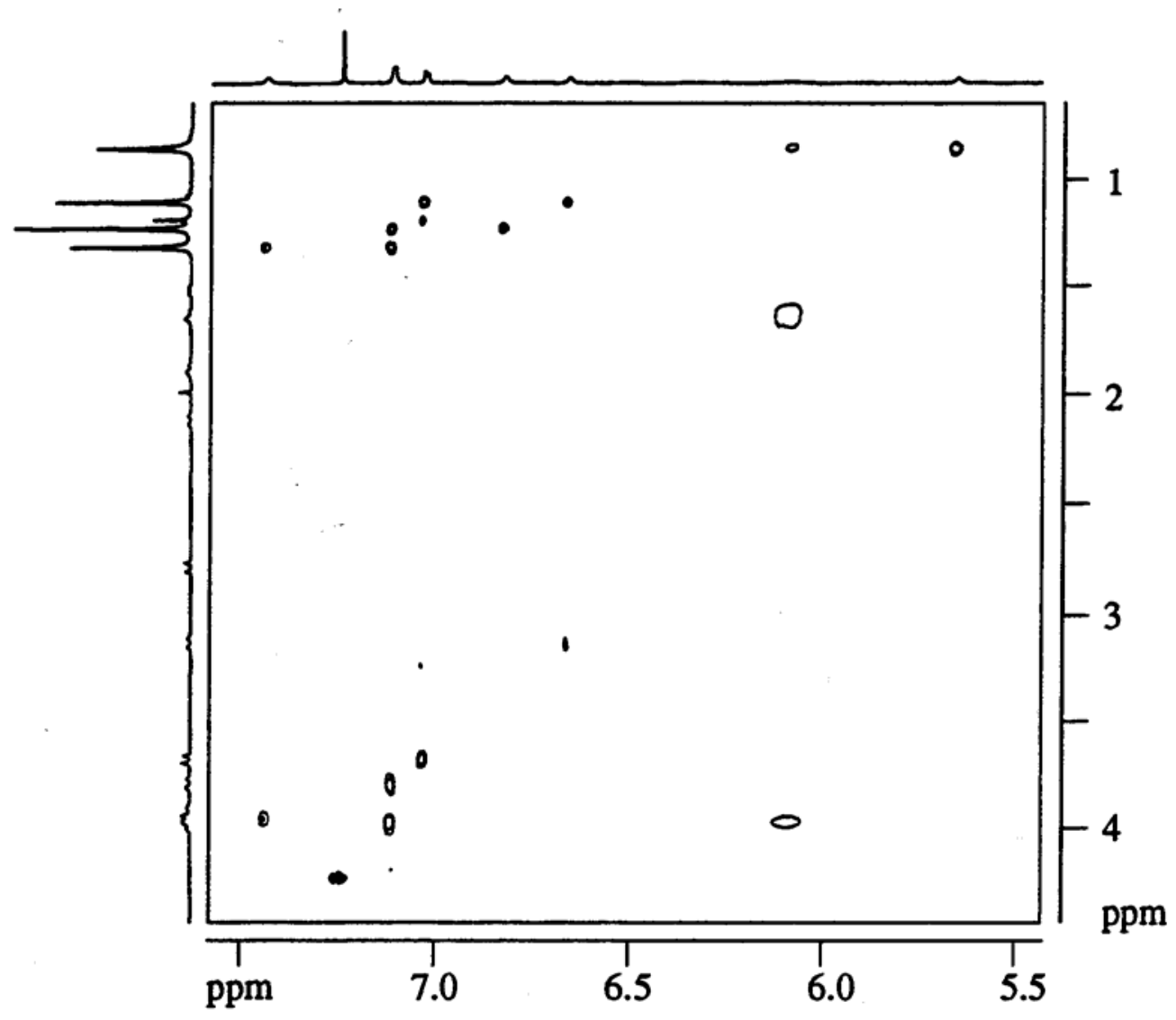

Figure 2. NOESY spectrum of 4.

The vinyl proton at $\delta 5.65 \mathrm{ppm}$ (signal 8 in Figure 1) is NOESY correlated to the tert-Bu signal at $\delta 0.86 \mathrm{ppm}$ (24) (Figure 2). In addition, (8) is COSY correlated to two aliphatic proton signals ((18) and (11)) and to a signal assigned to a proton of a vicinal methylene bridge (15). This methylene group ((15) and (12)) is COSY correlated to an aromatic signal at $\delta 6.65 \mathrm{ppm}(6)$ which is COSY correlated to the aromatic proton at $\delta 7.02 \mathrm{ppm}$ (4). Both signals (4) and (6) present NOE cross peaks with the tert-Bu signal at $\delta 1.11 \mathrm{ppm}(23)$. This phenol ring is vicinal to a second phenol ring as deduced from the NOE correlations between (4) - (10) and (10)-(1). The rest of the signals could not be assigned unequivocally (Figure 3). However, based on the NMR and MS data, we were able to tentatively ascribe structure 4 to the molecule. 


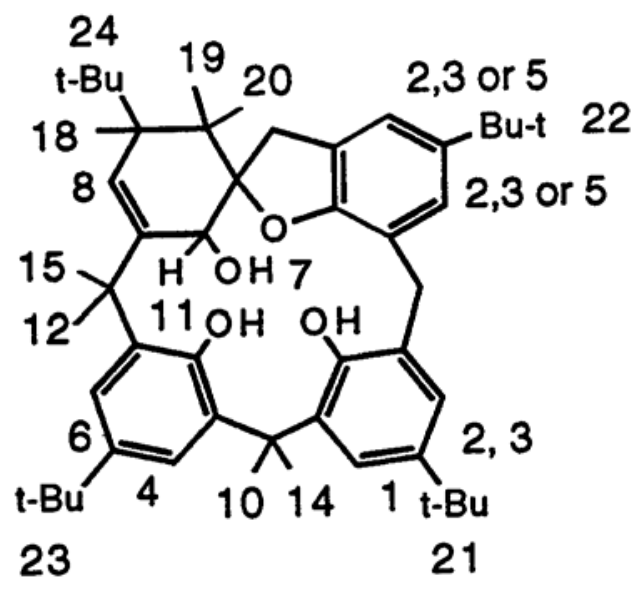

Figure 3. Partial assignment of the ${ }^{1} \mathrm{H}$ NMR signals of 4 .

Crystal structure of 4 . Corroboration of the proposed structure was obtained by X-ray crystallography. A single crystal of $\mathbf{4}$ was grown from $\mathrm{MeCN}$. The structure and the numbering scheme of the molecule are shown in Figure 4 and a stereoview of the crystal structure is shown in Figure 5. Positional parameters are collected in Table 1.

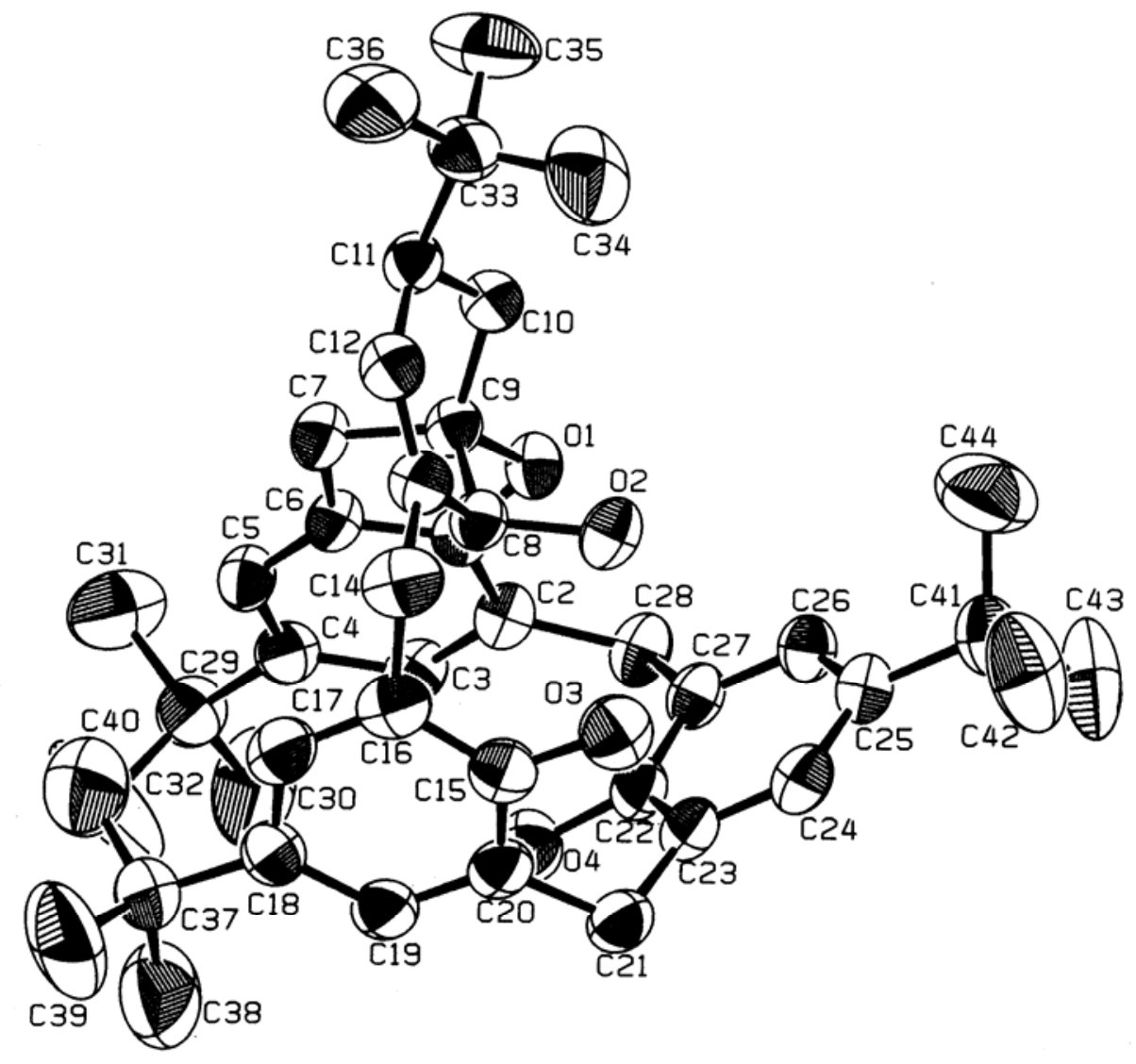

Figure 4. Structure and numbering scheme of 4. 
Table 1. Positional parameters of 4

\begin{tabular}{|c|c|c|c|c|}
\hline atom & $\mathbf{x}$ & $y$ & $\mathbf{z}$ & occupancy \\
\hline $\begin{array}{l}O(1) \\
O(2) \\
O(3) \\
O(4) \\
C(1) \\
C(2) \\
C(3) \\
C(4) \\
C(5) \\
C(6) \\
C(7) \\
C(8) \\
C(9) \\
C(10) \\
C(11) \\
C(12) \\
C(13) \\
C(14) \\
C(15) \\
C(16) \\
C(17) \\
C(18) \\
C(19) \\
C(20) \\
C(21) \\
C(22) \\
C(23) \\
C(24) \\
C(25) \\
C(26) \\
C(27) \\
C(28) \\
C(29) \\
C(30) \\
C(31) \\
C(32) \\
C(30 *) \\
C(31 \star) \\
C(32 \star) \\
C(33) \\
C(34) \\
C(35) \\
C(36) \\
C(37) \\
C(38) \\
C(39) \\
C(40) \\
C(41) \\
C(42) \\
C(43)\end{array}$ & $\begin{array}{l}0.34779(7) \\
0.35995(8) \\
0.30102(9) \\
0.21128(8) \\
0.2972(1) \\
0.2759(1) \\
0.2260(1) \\
0.1976(1) \\
0.2187(1) \\
0.2685(1) \\
0.3009(1) \\
0.3259(1) \\
0.3452(1) \\
0.4030(1) \\
0.4016(1) \\
0.3641(1) \\
0.3301(1) \\
0.2960(1) \\
0.2523(1) \\
0.2460(1) \\
0.1957(1) \\
0.1526(1) \\
0.1622(1) \\
0.2120(1) \\
0.2242(1) \\
0.2645(1) \\
0.2716(1) \\
0.3234(1) \\
0.3689(1) \\
0.3601(1) \\
0.3089(1) \\
0.3022(1) \\
0.1442(1) \\
0.1288(4) \\
0.1552(3) \\
0.0933(3) \\
0.0994(6) \\
0.1604(6) \\
0.124(1) \\
0.4609(1) \\
0.4901(2) \\
0.4971(2) \\
0.4566(2) \\
0.0992(1) \\
0.0611(2) \\
0.0661(2) \\
0.1155(2) \\
0.4257(1) \\
0.4318(3) \\
0.4343(4)\end{array}$ & $\begin{array}{l}0.5258(1) \\
0.3855(1) \\
0.2419(1) \\
0.3672(1) \\
0.5536(2) \\
0.5275(2) \\
0.5689(2) \\
0.6308(2) \\
0.6492(2) \\
0.6099(2) \\
0.6172(2) \\
0.4581(2) \\
0.5439(2) \\
0.5677(2) \\
0.5824(2) \\
0.5172(2) \\
0.4600(2) \\
0.3912(2) \\
0.2921(2) \\
0.3596(2) \\
0.4056(2) \\
0.3903(2) \\
0.3254(2) \\
0.2770(2) \\
0.2167(2) \\
0.3303(2) \\
0.2525(2) \\
0.2111(2) \\
0.2450(2) \\
0.3244(2) \\
0.3685(2) \\
0.4537(2) \\
0.6776(2) \\
0.6504(8) \\
0.7761(4) \\
0.651(1) \\
0.614(1) \\
0.718(1) \\
0.752(2) \\
0.5870(2) \\
0.4993(3) \\
0.6548(3) \\
0.6169(3) \\
0.4471(2) \\
0.4286(4) \\
0.4292(4) \\
0.5437(3) \\
0.1983(2) \\
0.1212(6) \\
0.1626(7)\end{array}$ & $\begin{array}{l}0.14224(8) \\
0.22134(9) \\
0.2490(1) \\
0.0469(1) \\
0.1007(1) \\
0.0365(1) \\
0.0003(1) \\
0.0266(1) \\
0.0936(1) \\
0.1300(1) \\
0.2009(1) \\
0.2315(1) \\
0.2093(1) \\
0.2525(1) \\
0.3231(1) \\
0.3421(1) \\
0.3031(1) \\
0.3281(1) \\
0.2326(1) \\
0.2748(1) \\
0.2582(2) \\
0.2007(2) \\
0.1598(1) \\
0.1740(1) \\
0.1236(1) \\
0.0638(1) \\
0.0994(1) \\
0.1134(1) \\
0.0956(1) \\
0.0628(1) \\
0.0459(1) \\
0.0082(1) \\
-0.0152(1) \\
-0.0867(4) \\
-0.0096(4) \\
0.0109(7) \\
-0.039(1) \\
-0.0745(8) \\
0.0234(8) \\
0.3732(1) \\
0.3802(2) \\
0.3495(2) \\
0.4390(2) \\
0.1832(2) \\
0.1147(3) \\
0.2304(3) \\
0.1857(3) \\
0.1120(2) \\
0.1582(5) \\
0.0472(3)\end{array}$ & $\begin{array}{l}0.667 \\
0.667 \\
0.667 \\
0.333 \\
0.333 \\
0.333\end{array}$ \\
\hline
\end{tabular}


Table 1. Continued

\begin{tabular}{|c|c|c|c|c|}
\hline atom & $\mathbf{x}$ & $y$ & $\mathbf{z}$ & occupancy \\
\hline $\begin{array}{l}C(44) \\
C(42 *) \\
C(43 \star) \\
C(44 *) \\
H(102) \\
H(103) \\
H(104) \\
H(3) \\
H(5) \\
H(8) \\
H(11) \\
H(12) \\
H(17) \\
H(19) \\
H(24) \\
H(26) \\
H(71) \\
H(72) \\
H(101) \\
H(102) \\
H(141) \\
H(142) \\
H(211) \\
H(212) \\
H(281) \\
H(282) \\
H(341) \\
H(342) \\
H(343) \\
H(351) \\
H(352) \\
H(353) \\
H(361) \\
H(362) \\
H(363) \\
H(381) \\
H(382) \\
H(383) \\
H(391) \\
H(392) \\
H(393) \\
H(401) \\
H(402) \\
H(403)\end{array}$ & 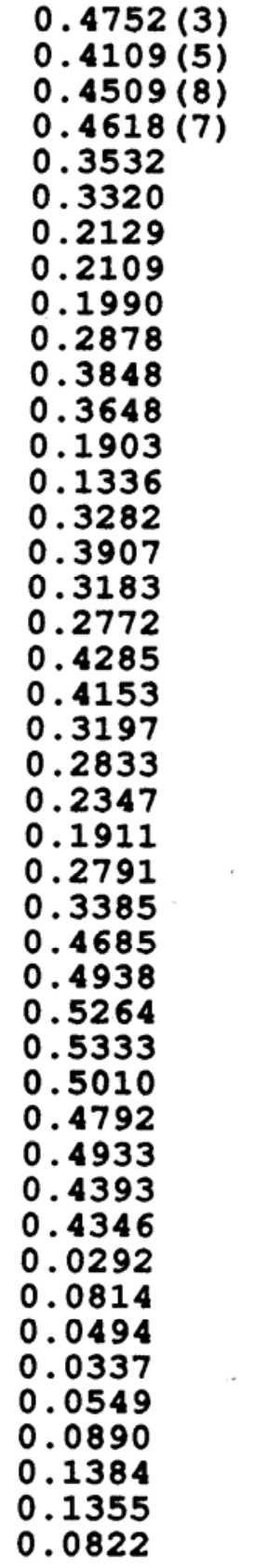 & 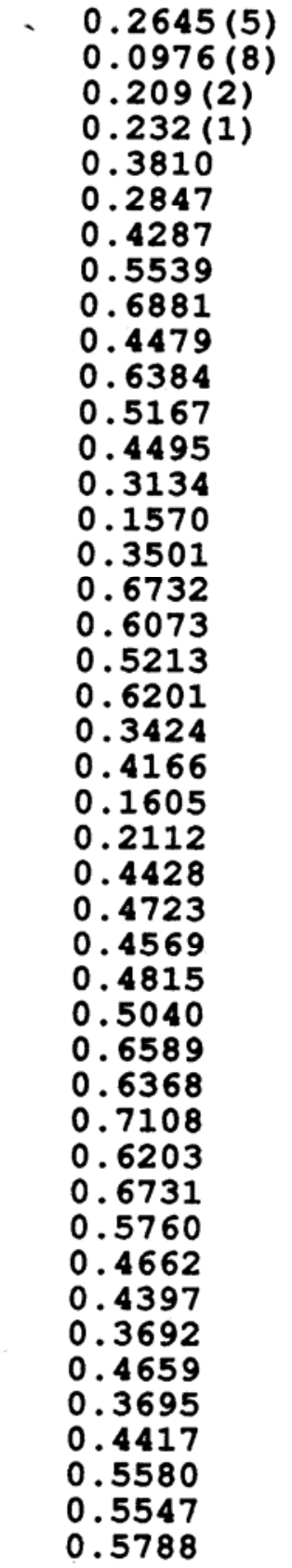 & 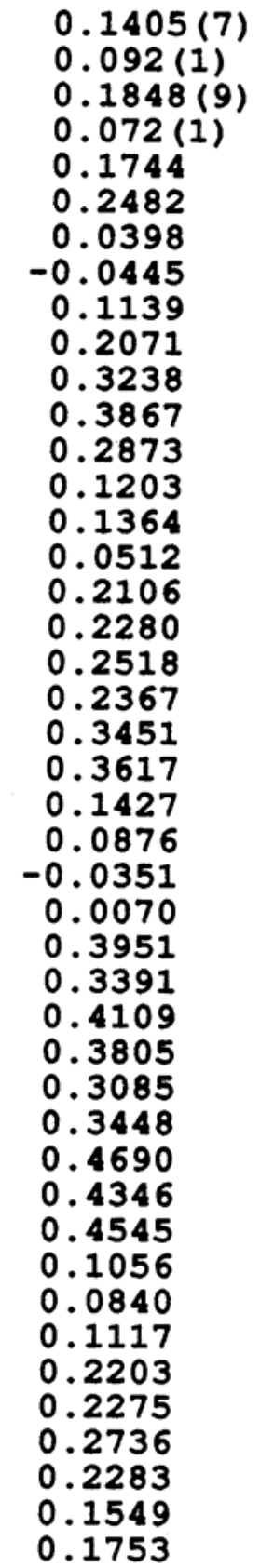 & $\begin{array}{l}0.667 \\
0.333 \\
0.333 \\
0.333\end{array}$ \\
\hline
\end{tabular}

The arrangement of the rings of $\mathbf{4}$ resembles the partial-cone conformation adopted by $\mathbf{3 a}$ in the crystal. ${ }^{7 b}$ The molecule possesses three chiral centers: the secondary alcohol carbon, the spiro carbon and the $\mathrm{sp}^{3}$ carbon substituted by a tert-Bu group. All these stereogenic carbons belong to 
the same partially reduced ring, and they induce a distortion from the partial cone conformation adopted by $3 a^{7 b}{ }^{7 b}$ The spiro oxygen atom is cis to the secondary $\mathrm{OH}$ group and to the tert-butyl group. The relative configurations of the three stereocenters indicate that the hydrogens attached to the $\mathrm{COH}$ and $\mathrm{C}-\mathrm{Bu}-\mathrm{t}$ carbons were delivered to the exo face (i.e., anti to the spiro $\mathrm{C}-\mathrm{O}$ bond) of the carbonyl and diene groups. NMR analysis of the bis(spirodienol) derivative obtained by $\mathrm{NaBH}_{4}$ reduction of $\mathbf{2 a}$ has shown that the reaction proceeds via exo attack. ${ }^{15}$ The alcoholic OH group and its vicinal phenolic oxygen atoms are pointing to the same side (i. e., "up") of the mean plane of the molecule. These three atoms are connected by two hydrogen bonds as judged by the short O-O distances; $(\mathrm{O}(1)-\mathrm{O}(2): 2.686 \AA, \mathrm{O}(2)-\mathrm{O}(3)$ : 2.786 (3) $\AA$ ). The phenolic $\mathrm{OH}$ group distal to the reduced ring is pointing to the opposite side of the molecular mean plane (i.e., "down"). On the basis of the 2D NMR data, the lowest field signal in the ${ }^{1} \mathrm{H}$ NMR spectrum (i.e., (1)) was assigned to the aromatic proton of the aryl ring opposite to the reduced ring. Assuming that the molecule adopts the same conformation in solution as in the crystal, the peculiar chemical shift of proton (1) may be explained by the presence of two $\mathrm{OH}$ groups in its steric proximity.
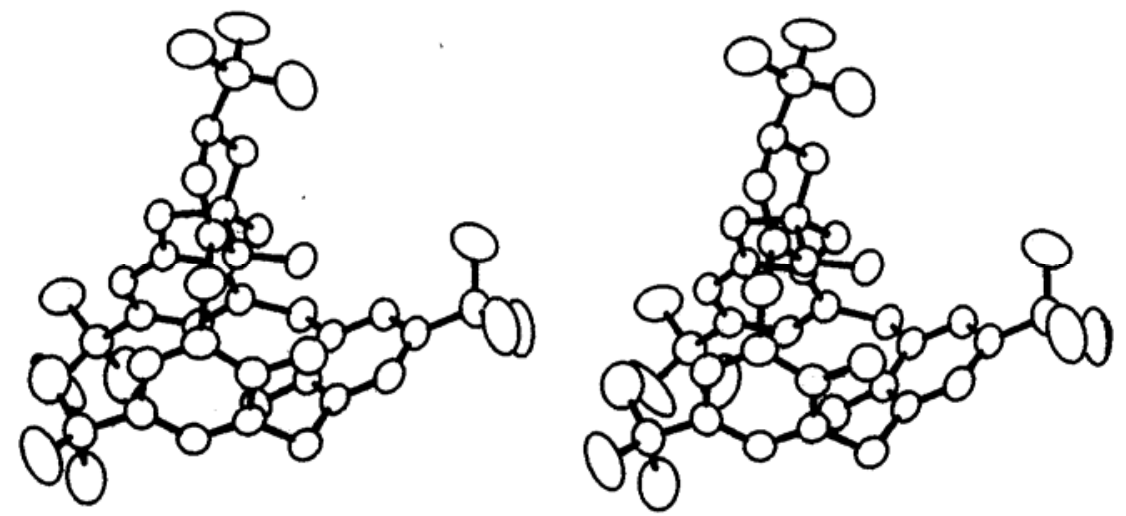

Figure 5. Stereoscopic view of the crystal structure of 4.

The formation of $\mathbf{4}$ is probably the result of the reduction of a carbonyl group and a double bond of one spirodienone subunit and the reductive cleavage of the spiro C-O bond on the second spirodienone unit. Notably, the formation of $\mathbf{4}$ requires the reduction of one of the dienone double bonds of 2a. A similar behavior was observed in the reaction of 2a with hydrazine, where 5 was obtained. ${ }^{14}$ In the case of $\mathbf{4}$ the spiro C-O bond on the reduced ring is not cleaved under the reaction conditions, suggesting that the reduction of the double bond is faster than the C-O cleavage. This $\mathrm{C}-\mathrm{O}$ bond is not cleaved under the reaction conditions, since after the double bond is reduced, the cleavage would not result in rearomatization, eliminating one of the driving forces for the process . 


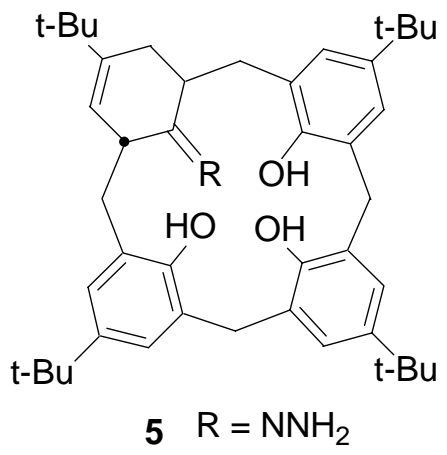

\section{Experimental Section}

\section{Reaction of the bis(spirodienone) calixarene derivative 2a with hydrazine}

A suspension of $2 \mathbf{a}(200 \mathrm{mg}, 0.31 \mathrm{mmol})$ and $\mathrm{H}_{2} \mathrm{NNH}_{2} \cdot \mathrm{H}_{2} \mathrm{O}(2.5 \mathrm{~mL})$ in $80 \mathrm{~mL}$ isopropanol were heated to $160{ }^{0} \mathrm{C}$ during $4 \mathrm{hrs}$ in a pressure reactor while stirring magnetically. The mixture was allowed to reach room temperature and $\mathbf{1}$ was filtered form the reaction mixture. The solvent was evaporated yielding $126 \mathrm{mg}$ of the crude product. The residue was triturated with $\mathrm{MeOH}$ and filtrated. Evaporation of the filtrate afforded 4 (35 mg, $0.054 \mathrm{mmol}, 17 \%)$. Further purification was achieved by recrystallization from $\mathrm{CH}_{2} \mathrm{Cl}_{2} / \mathrm{CH}_{3} \mathrm{CN}$, mp: $272-274{ }^{\circ} \mathrm{C}$.

${ }^{1} \mathrm{H}$ NMR (400 MHz, $\left.\mathrm{CDCl}_{3}, \mathrm{rt}\right) \delta 0.86$ (s, 9H, t-Bu), 1.11 (s, 9H, t-Bu), 1.23 (s, 9H, t-Bu), 1.31(s, 9H, t-Bu), 1.52 (m, 1H, $\mathrm{CH}_{2}$ ), 1.64 (s, $\left.1 \mathrm{H}, \mathrm{CH}_{2}\right), 1.89$ (m, 2H, $\left.\mathrm{CH}_{2}, \mathrm{CH}\right), 2.11$ (d, 1H, $J=15.9 \mathrm{~Hz}, \mathrm{CH}_{2}$ ), 2.78 (d, $1 \mathrm{H}, J=15.8 \mathrm{~Hz}, \mathrm{CH}_{2}$ ), 3.13 (d, $\left.1 \mathrm{H}, J=16.4 \mathrm{~Hz}, \mathrm{CH}_{2}\right), 3.66$ (d, $1 \mathrm{H}, J=$ $13.2 \mathrm{~Hz}, \mathrm{CH}_{2}$ ), 3.77 (d, 1H, J= $15.6 \mathrm{~Hz}, \mathrm{CH}_{2}$ ), 3.95 (m, 3H, $\mathrm{CH}_{2}, \mathrm{CH}-\mathrm{OH}$ ), 5.65 (s br,1H, CH), 6.08 (s broad, 1H, OH), 6.65 (s broad, 1H, ArH), 6.82 (s broad, 1H, ArH), 7.02 (d, 1H, J=2.4 Hz, ArH), 7.11 (s broad, 2H, ArH) and 7.43 (s broad, 1H, ArH). ${ }^{13} \mathrm{C}$ NMR (100.62 $\mathrm{MHz}, \mathrm{CDCl}_{3}, \mathrm{rt}$ ) $\delta$ 22.68, 29.35, 29.69, 31.39, 31.50, 31.61,31.65, 33.13, 33.68, 33.90, 34.00, 34.25, 36.05, 36.77, 66.89 (C(sp $\left.\left.{ }^{3}\right)-\mathrm{OH}\right), 91.47$ (C(sp3)-OAr), 120.70, 121.59, 124.35, 124.98, 125.47, 125.93, 127.08, 127.53, 128.14, 129.11, 130.00, 144.97, 145.24, 151.49, 153.94 ppm. IR: $v 3502(\mathrm{OH})$ and 3316 $(\mathrm{OH}) \mathrm{cm}^{-1}$. CI MS: m/z $649.0\left(\mathrm{MH}^{+}-\mathrm{H}_{2}\right)$. Anal. calcd. for $\mathrm{C}_{44} \mathrm{H}_{58} \mathrm{O}_{4} \cdot \mathrm{H}_{2} \mathrm{O}: \mathrm{C}: 79.00$, H: 9.04. Found: C: 79.26, H: 8.88.

Crystallography. Crystal data for 4: formula: $\mathrm{C}_{44} \mathrm{H}_{58} \mathrm{O}_{4}$, space group $C 2 / \mathrm{c}, a=24.793(3) \AA$, $b=15.217(3) \AA, c=21.409(4) \AA, \beta=106.98(1)^{\circ}, V=7725(3) \AA^{3}, Z=8, D_{c}=1.12 \mathrm{Mg} \mathrm{m}^{-3}, \mu\left(\mathrm{CuK}_{\alpha}\right)$ $=5.09 \mathrm{~cm}^{-1}$, no. of unique reflections $=5543$, no. of reflections with $\mathrm{I} \geq 3 \sigma_{\mathrm{I}}=4349, R_{1}=0.059$, $R_{w}=0.088$. Data were measured on an ENRAF-Nonius CAD-4 computer-controlled diffractometer. $\operatorname{CuK}_{\alpha}(\lambda=1.54178 \AA)$ radiation with a graphite crystal monochromator in the incident beam was used. All crystallographic computing was done on a VAX 9000 computer using the TEXSAN structure analysis software. 


\section{Ackowledgements}

We thank Dr. Shmuel Cohen for the crystal structure determination. This research was supported by the Israel Science Foundation (grant No. 44/01-1).

\section{References}

1. For reviews on calixarenes see: (a) Gutsche, C. D. Calixarenes Revisited Royal Society of Chemistry: Cambridge, 1998. (b) Böhmer, V. Angew. Chem., Int. Ed. Engl. 1995, 34, 713. (c) Gutsche, C. D. Aldrichimica Acta 1995, 28, 1. (d) Gutsche, C. D. Calixarenes; Royal Society of Chemistry: Cambridge, 1989. (e) Calixarenes 2001 Asfari, Z.; Böhmer, V.; Harrowfield, J.; Vicens, J.; Eds., Kluwer Academic Publishers: Dordrecht, 2001.

2. (a) Litwak, A. M.; Biali, S. E. J. Org. Chem. 1992, 57, 1943. (b) Litwak, A. M.; Grynszpan, F.; Aleksiuk, O.; Cohen, S.; Biali, S. E. J. Org. Chem. 1993, 58, 393.

3. For reviews on spirodienone calixarene derivatives see: (a) Aleksiuk, O.; Grynszpan, F.; Litwak, M. A.; Biali, S. E. New J. Chem. 1996, 20, 473; (b) Biali, S. E. in ref 2, pp 266-279.

4. For the preparation of spirodienone derivatives of larger calixarenes see for example: (a) Grynszpan, F.; Biali, S. E. J. Org. Chem 1996, 61, 9512. (b) Agbaria, K.; Aleksiuk, O.; Biali, S. E.; Böhmer, V.; Frings, M.; Thondorf, I. J. Org. Chem. 2001, 66, 2891.

5. For spirodienone derivatives of calixnaphthols and dihydroxymetacyclophanes see: Georghiou, P. E.; Ashram, M.; Clase, H. J.; Bridson, J. N. J. Org. Chem. 1998, 63, 1819. Yamato, T.; Matsumoto, T.; Sato, J. M.; Fujita, K.; Nagano, Y. J. Chem. Research (S) 1997, 74 J. Chem. Research (M) 1997, 518.

6. Wang, W.-G.; Zhang, W.-C.; Huang, Z.-T. J. Chem. Res. (S) 1998, 462.

7. (a) Van Gelder, J. M.; Brenn, J.; Thondorf, I.; Biali, S.E. J. Org. Chem. 1997, 62, 3511. (b) Aleksiuk, O.; Grynszpan, F.; Biali, S. E. J. Chem. Soc. Chem. Commun. 1993, 11.

8. (a) Aleksiuk, O.; Cohen, S.; Biali, S. E. J. Am. Chem. Soc. 1995, 117, 9645. (b) Aleksiuk, O.; Biali, S. E. J. Org. Chem. 1996, 61, 5670 (c) Agbaria, K.; Biali, S. E. J. Org. Chem. 2001, 66, 5482.

9. (a) Agbaria, K.; Biali, S. E. J. Am. Chem. Soc. 2001, 123, 12495. (b) Simaan, S., Agbaria, K.; Biali, S. E. J. Org. Chem. 2002, 67, 6136.

10. (a) Goren, Z.; Biali, S. E. J. Chem. Soc., Perkin Trans. 1 1990, 1484. See also: (b) Grynszpan, F.; Biali, S. E. Tetrahedron Lett. 1991, 38, 5155. (c) Ting , Y.; Verboom W.; Groenen, L. C.; van Loon, J. -D.; Reinhoudt, D. N. J. Chem. Soc. Chem. Commun. 1990, 1432. (c) McMurry, J. E.; Phelan, J. C. Tetrahedorn Lett. 1991, 32, 5655 (d) Regnouf de Vains, J. B. R.; Pellet-Rostaing, S.; Lamartine, R. Tetrahedron Lett. 1994, 35, 8147. (e) Matsuda, K.; Nakamura, N.; Takahashi, K.; Inoue, K.; Koga, N.; Iwamura, H. J. Am. Chem. Soc. 1995, 117, 5550. (f) Sachleben, R. A.; Urvoas, A.; Bryan, J. C.; Haverlock, T. J.; Moyer, B. A.; Hay, B. P. Chem. Commun. 1999, 175.

11. Rossi, R.A.; Bunnett, J. F. J. Org. Chem. 1973, 38, 2314. 
12. Ohseto, F.; Murakami, H.; Araki,K.; Shinkai, S. Tetrahedron Lett., 1992, 33, 1217. See also: Grynszpan, F.; Aleksiuk, O.; Biali, S. E. J. Org. Chem. 1994, 59, 2070.

13. Katagiri, H.; Iki, N.; Hattori, T; Kabuto, C.; Miyano, S. J. Am. Chem. Soc. 2001, 123, 779.

14. Aleksiuk, O.; Grynszpan, F.; Biali, S. E. J. Org. Chem. 1993, 58, 1994.

15. Agbaria, K.; Wöhnert, J.; Biali, S. E. J. Org. Chem. 2001, 66, 7059. 